\title{
Ni nanoparticles on RGO as reusable heterogeneous catalyst: effect of Ni particle size and intermediate composite structures in $\mathrm{C}-\mathrm{S}$ cross-coupling reaction
}

\author{
Debasish Sengupta ${ }^{\ddagger 1}$, Koushik Bhowmik ${ }^{\ddagger 2}$, Goutam De ${ }^{\star 2}$ and Basudeb Basu*1
}

\author{
Full Research Paper \\ Address: \\ ${ }^{1}$ Department of Chemistry, University of North Bengal, Darjeeling \\ 734013, India. Fax: +91353 2699001; Tel: +91 3532776381 and \\ ${ }^{2}$ Nano-Structured Materials Division, CSIR-Central Glass \& Ceramic \\ Research Institute, 196, Raja S. C. Mullick Road, Jadavpur, Kolkata \\ 700032, India. Fax: +9133 24730957; Tel: +913323223403 \\ Email: \\ Goutam De* - gde@cgcri.res.in; Basudeb Basu* - \\ basu_nbu@hotmail.com \\ * Corresponding author $\ddagger$ Equal contributors \\ Keywords: \\ C-S cross-coupling; heterogeneous catalyst; Ni nanoparticle; reduced \\ graphene oxide; thioether
}

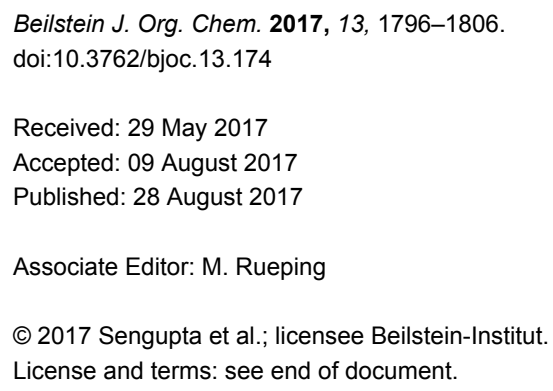

\begin{abstract}
The present work demonstrates the $\mathrm{C}-\mathrm{S}$ cross-coupling reaction between aryl halides and thiols using nickel nanoparticles (Ni NPs) supported on reduced graphene oxide $(\mathrm{Ni} / \mathrm{RGO})$ as a heterogeneous catalyst. It is observed that the uniformly dispersed Ni NPs supported on RGO could exhibit excellent catalytic activity in $\mathrm{C}-\mathrm{S}$ cross-coupling reactions and the catalytic application is generalized with diverse coupling partners. Although the electron-rich planar RGO surface helps in stabilizing the agglomeration-free $\mathrm{Ni}$ $\mathrm{NPs}$, the catalytic process is found to occur involving $\mathrm{Ni}$ (II) species and the recovered catalyst containing both $\mathrm{Ni}(0) / \mathrm{Ni}(\mathrm{II})$ species is equally efficient in recycle runs. A correlation of loading of Ni species, size of NPs and the intermediate Ni-related heterostructures formed during the catalytic process has been established for the first time, and found to be best in the C-S cross-coupling reaction for $\mathrm{Ni}(0)$ and $\mathrm{Ni}(\mathrm{II}) \mathrm{NPs}$ of the average sizes $11-12 \mathrm{~nm}$ and $4 \mathrm{~nm}$, respectively.
\end{abstract}

\section{Introduction}

The formation of a carbon-sulfur bond is an imperative step for the synthesis of many biologically active chemical entities that have significant applications in different therapeutic areas such as HIV, cancer, diabetes, inflammation, Alzheimer's and
Parkinson's diseases etc. [1-4]. The first palladium-catalyzed arylation of thiols was reported by Migita and co-workers in 1980 [5], and soon after Cristau and co-workers developed a nickel-catalyzed route for $\mathrm{C}-\mathrm{S}$ cross-coupling reactions [6]. 
Other metals such as copper [7], cobalt [8], iron [9], rhodium [10], manganese [11], indium [12], and bismuth [13] have been used with specific electron-rich ligands in the $\mathrm{C}-\mathrm{S}$ coupling reactions. However, these are less common compared to other $\mathrm{C}-\mathrm{X}(\mathrm{X}=\mathrm{C}, \mathrm{O}, \mathrm{N}, \mathrm{P})$ coupling reactions, presumably because sulfur might suppress the catalytic function through its coordinating and adsorptive properties [14]. The Ni-catalyzed C-S cross-coupling reactions generally involved $\mathrm{Ni}$ salts [15-18], $\mathrm{Ni}-$ phosphine complexes [19-21], or Ni-NHC complexes $[22,23]$, although the actual catalyst is believed to be a $\mathrm{Ni}(0) / \mathrm{Ni}(\mathrm{I})$ species [16-21]. NiO supported on zirconia $\left(\mathrm{NiO}-\mathrm{ZrO}_{2}\right)$ is thus far known to act as the only heterogeneous nanocatalyst for $\mathrm{C}-\mathrm{S}$ cross-coupling with limited applications and poor yields [24].

In recent years, graphene-based composite materials have become popular because of their unique physical, mechanical and chemical properties [25-27]. Graphene, a single atomic layer of conjugated $\mathrm{sp}^{2}$ carbon atoms with a large contact area, can adopt several guest particles [28,29]. Reduced graphene oxide (RGO) with a high surface area can be easily dispersed in aqueous or non-aqueous media and can be mingled with other nanomaterials to produce stable nanocomposites [30]. Therefore, RGO is considered an excellent candidate for catalyst support [31,32]. To date, various magnetic or semiconducting nanoparticles (NPs) have been incorporated in GO surfaces and thoroughly studied in terms of their photocatalytic and electrochemical properties [33-37]. However, only few graphenebased metal nanocomposites have been recognized for organic cross-coupling reactions [38-42]. In general, bare Ni NPs are very unstable and readily oxidized in air [43]. A few literature reports are available where $\mathrm{Ni}$ species immobilized on a solid surface have been used in $\mathrm{C}-\mathrm{C}$ or $\mathrm{C}-\mathrm{N}$ cross-coupling reactions [44-47]. We have recently shown that uniformly dispersed Ni NPs that are free of agglomeration can be embedded in RGO sheets $(\mathrm{Ni} / \mathrm{RGO})$. This very stable $\mathrm{Ni} / \mathrm{RGO}$ nanocomposite enhances the reduction rate of $\mathrm{Cr}(\mathrm{VI})$ species to $\mathrm{Cr}(\mathrm{III})$ in the presence of formic acid at room temperature [48]. Also, it can serve as an excellent catalyst for the Kumada-Corriu C-C cross-coupling reaction [49]. Since heterogeneous Ni catalysts are rarely studied for the $\mathrm{C}-\mathrm{S}$ cross-coupling reaction between aryl halides and thiols, presumably because of the fact that the thiols (bearing $-\mathrm{S}-\mathrm{H}$ ) might poison the catalyst, we became interested to examine this catalyst. Herein, we present our studies which revealed that both $\mathrm{Ni}(0)$ and $\mathrm{Ni}(\mathrm{II})$ species formed during the reaction and remaining on RGO could act as the active catalysts for the $\mathrm{C}-\mathrm{S}$ cross-coupling reaction. Moreover, a correlation between the loading of metal, the effect of average $\mathrm{NP}$ size of $\mathrm{Ni}(0) / \mathrm{Ni}(\mathrm{II})$ species in the catalyst and the intermediate composite heterostructures has been established for the first time.

\section{Results and Discussion}

We synthesized $\mathrm{Ni} / \mathrm{RGO}$ nanocomposites following our reported method $[48,49]$. These materials were well characterized by powder XRD, TEM, TGA and XPS studies. The preparation and characterization of the nanocomposites were described in detail in our previous publications [48,49]. Usually, bare $\mathrm{Ni}$ NPs are unstable and likely to undergo aerial oxidation [43]. However, in the Ni/RGO composite, the electron-rich RGO surface helps in stabilizing the $\mathrm{Ni}$ in its zero-valent state. The high surface area and planar structure of RGO prevent the Ni NPs (to an optimum loading of $\mathrm{Ni}$ ) from agglomeration and provide enough adsorption sites to the reacting molecules. In this work graphene oxide (GO) was used as a support for in situ growth of Ni nanoparticles. The synthetic protocol presumably allows initial interaction between the metal and functional groups on to the basal plane of GO [48]. The interaction could take place effectively due to the planar structure and large contact area of GO. As a result, when reduced, the Ni nanoparticles could sit on the RGO surface without agglomeration.

We prepared three different $\mathrm{Ni} / \mathrm{RGO}$ nanocomposites by varying the loading of Ni NPs. The crystallite sizes of Ni NPs in these three $\mathrm{Ni}(0) / \mathrm{RGO}$ samples were calculated with X-ray line broadening using the (111) and (200) peaks as reported [48,49] (see also Supporting Information File 1). The average crystallite sizes of Ni NPs are 10, 11 and $17 \mathrm{~nm}$ in Ni/RGO-20 (20 wt \% Ni), Ni/RGO-40 (40 wt \% Ni) and Ni/RGO-60 (60 wt \% Ni) samples, respectively. It was observed that an optimum loading of $40 \mathrm{wt} \% \mathrm{Ni}$ in $\mathrm{Ni} / \mathrm{RGO}$ could be loaded without any agglomeration with a restriction of average size $\approx 11 \mathrm{~nm}$. However, if the loading is increased to $60 \mathrm{wt} \%$, the average size of NPs becomes significantly higher $(17 \mathrm{~nm})$ due to agglomeration. Therefore, we found Ni/RGO-40 (40 wt \% Ni) is very suitable for our catalytic reactions.

We began our studies on optimizing the reaction taking 3-iodoanisole and benzenethiol as model coupling partners and $\mathrm{Ni} / \mathrm{RGO}$ as the catalyst. In the process, we first examined the coupling reactions with $\mathrm{Ni} / \mathrm{RGO}-40$ at varying temperatures, bases and solvents, though other nanocomposites (Ni/RGO-20 and Ni/RGO-60) were also tested (Table 1). All reactions were carried out under a $\mathrm{N}_{2}$ atmosphere to avoid oxidative dimerization of thiols to disulfide [50]. Solvent optimization was started with water (Table 1, entry 1 ) followed by toluene (Table 1 , entry 2) and isolating diaryl sulfide only $6-8 \%$ after $10 \mathrm{~h}$, while in DMSO the yield significantly rises to $86 \%$ within $3 \mathrm{~h}$ (Table 1, entry 3 ). The conversion was even higher (92\%) when DMSO was replaced with DMF (Table 1, entry 4). However, a drop in the catalyst loading or a lowering of the temperature affected the course of the reaction by suppressing the overall yield of the thioether (Table 1, entries 5 and 6). Without using 
Table 1: Optimization of the C-S cross-coupling reaction conditions using Ni/RGO-40. ${ }^{a}$

\begin{tabular}{|c|c|c|c|c|c|c|}
\hline Entry & $\begin{array}{c}\text { Catalyst } \\
\text { Ni content (mol \%) }\end{array}$ & Solvent & Base & Temperature $\left({ }^{\circ} \mathrm{C}\right)$ & Time $(\mathrm{h})$ & Yield $^{\mathrm{b}}(\%)$ \\
\hline 1 & 15 & water & $\mathrm{K}_{2} \mathrm{CO}_{3}$ & 100 & 10 & 8 \\
\hline 2 & 15 & toluene & $\mathrm{K}_{2} \mathrm{CO}_{3}$ & 100 & 10 & 6 \\
\hline 3 & 15 & DMSO & $\mathrm{K}_{2} \mathrm{CO}_{3}$ & 100 & 3 & 86 \\
\hline 4 & 15 & DMF & $\mathrm{K}_{2} \mathrm{CO}_{3}$ & 100 & 3 & 92 \\
\hline 5 & 10 & DMF & $\mathrm{K}_{2} \mathrm{CO}_{3}$ & 100 & 3 & 81 \\
\hline 6 & 15 & DMF & $\mathrm{K}_{2} \mathrm{CO}_{3}$ & 80 & 10 & 61 \\
\hline 7 & 15 & DMF & None & 100 & 10 & 74 \\
\hline 8 & 15 & DMF & $\mathrm{KOH}$ & 100 & 3 & 83 \\
\hline $9^{c}$ & 15 & DMF & $\mathrm{K}_{2} \mathrm{CO}_{3}$ & 100 & 3 & 63 \\
\hline 10 & none & DMF & $\mathrm{K}_{2} \mathrm{CO}_{3}$ & 100 & 10 & 0 \\
\hline $11^{d}$ & RGO & DMF & $\mathrm{K}_{2} \mathrm{CO}_{3}$ & 100 & 10 & 0 \\
\hline $12^{\mathrm{e}}$ & 15 & DMF & $\mathrm{K}_{2} \mathrm{CO}_{3}$ & 100 & 3 & 91 \\
\hline $13^{f}$ & 15 & DMF & $\mathrm{K}_{2} \mathrm{CO}_{3}$ & 100 & 3 & 84 \\
\hline $14^{\mathrm{g}}$ & 15 & DMF & $\mathrm{K}_{2} \mathrm{CO}_{3}$ & 100 & 3 & 79 \\
\hline $15^{\mathrm{h}}$ & 15 & DMF & $\mathrm{K}_{2} \mathrm{CO}_{3}$ & 100 & 3 & 92 \\
\hline
\end{tabular}

a3-lodoanisole $(1 \mathrm{mmol})$, benzenethiol $(1.2 \mathrm{mmol}), \mathrm{K}_{2} \mathrm{CO}_{3}(1.2 \mathrm{mmol})$ and solvent $(3 \mathrm{~mL})$ heated at $100{ }^{\circ} \mathrm{C}$ under $\mathrm{N}_{2} .{ }^{\mathrm{b}}$ lsolated yield. ${ }^{\mathrm{c}}$ Reaction was performed without $\mathrm{N}_{2}$. ${ }^{C}$ Diphenyl disulfide was isolated $(15 \%)$. dRGO (13.2 mg). ${ }^{\mathrm{e}} \mathrm{Ni} / \mathrm{RGO}-20$ catalyst. ${ }^{\mathrm{f}} \mathrm{Ni} / \mathrm{RGO}-60 \mathrm{catalyst}$. 9Ni NPs. ${ }^{\mathrm{h}} 4-\mathrm{lodoanisole}$ $(1 \mathrm{~g}, 4.27 \mathrm{mmol})$, benzenethiol $(5.12 \mathrm{mmol}), \mathrm{K}_{2} \mathrm{CO}_{3}(5.12 \mathrm{mmol})$, Ni/RGO-40 catalyst $(94.0 \mathrm{mg}$; Ni content is $37.60 \mathrm{mg}, 0.64 \mathrm{mmol})$ and solvent $(4 \mathrm{~mL})$ heated at $100{ }^{\circ} \mathrm{C}$ under $\mathrm{N}_{2}$.

any base, the yield was $74 \%$, while the use of $\mathrm{KOH}$ as a base afforded the thioether in $83 \%$ yield (Table 1, entries 7 and 8 ). Formation of the diphenyl disulfide via oxidative dimerization of benzenethiol was noticed (15\%) when the reaction was carried out under aerobic conditions (Table 1, entry 9). Control experiments without the catalyst $(\mathrm{Ni} / \mathrm{RGO}-40)$ or only with RGO (Ni-free) did not produce any cross-coupled sulfane product (Table 1, entries 10 and 11). The reaction was then performed in the presence of $\mathrm{Ni} / \mathrm{RGO}-20$ and $\mathrm{Ni} / \mathrm{RGO}-60$ under similar conditions affording the thioether in $91 \%$ and $84 \%$ yields, respectively (Table 1, entries 12 and 13). These observations suggest that both $\mathrm{Ni} / \mathrm{RGO}-20$ and $\mathrm{Ni} / \mathrm{RGO}-40$ with average Ni NPs size $(\approx 10-11 \mathrm{~nm})$ have better catalytic efficiency (yield $91-92 \%$ ) than Ni/RGO-60 ( $\approx 17 \mathrm{~nm})$, presumably attributable to the larger active surface areas in the former two cases. On the other hand, bare Ni NPs (of an average size $\approx 10 \mathrm{~nm}$ ) prepared following the reported procedure [51], gave the corresponding cross-coupled product in $79 \%$ yield (Table 1, entry 14). This could be due to the agglomeration of NPs or further oxidation of Ni NPs in the absence of the electron-rich RGO surface.

Thus, the average size of Ni NPs supported with electron-rich RGO surface seems to be important to obtain maximum catalyt- ic efficiency in the $\mathrm{C}-\mathrm{S}$ coupling reaction. The catalytic reaction was found to be scalable with comparable conversions (Table 1 , entry 15 ).

We then extended the optimized reaction conditions (as in Table 1, entry 4) using Ni/RGO-40 to diverse functionalized aryl halide/thiol combinations. The results are indeed encouraging and summarized in Table 2. Both coupling partners, i.e., the iodoarenes and arylthiols bearing different groups like Me, $\mathrm{OMe}, \mathrm{F}, \mathrm{COCH}_{3}, \mathrm{NO}_{2}$ are equally efficient to undergo crosscoupling reactions producing the corresponding unsymmetrical diaryl sulfides 3a-i in $88-93 \%$ isolated yields (Table 2, entries 1-9). No significant influence of electron-donating or electronwithdrawing groups has been noticed, which is in agreement with previously reported results in C-S coupling reactions [19]. In the case of iodobromoarenes or iodochloroarenes, we obtained only iodo-coupled products $\mathbf{3} \mathbf{j}$ and $\mathbf{3 k}$ in excellent yields (Table 2, entries 10 and 11). Bromoarenes remain unchanged under the given conditions. However, the cross-coupling of bromoarenes could be performed efficiently in the presence of zinc dust ( 1 equivalent to the substrate bromoarene) in addition to a catalytic amount of Ni/RGO-40 (Table 2, entries 12 and 13). Although the exact role of zinc is not clearly understood, based on literature reports $[7,16]$, we presume that the oxidized 
Table 2: Ni/RGO-40 catalyzed C-S cross-coupling between aryl halide and thiol. ${ }^{a}$

$$
\begin{aligned}
& \text { aryl halide (1) } \\
& \mathrm{X}=\mathrm{I}, \mathrm{Br}, \mathrm{FG}=\text { functional group, } \mathrm{R}=\text { aryl, alkyl }
\end{aligned}
$$

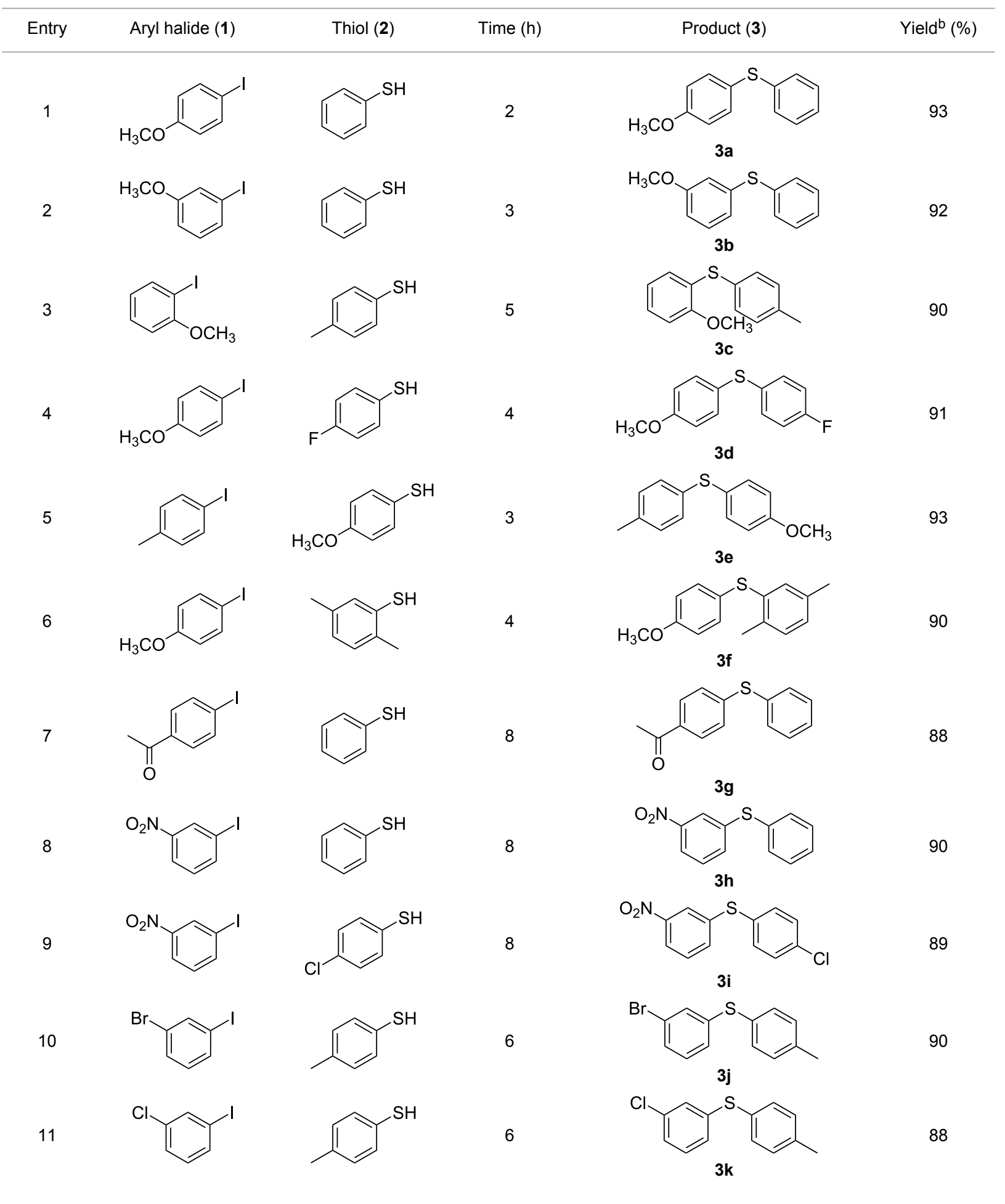


$12^{\mathrm{c}}$<smiles>COc1ccc(Br)cc1C</smiles>

$13^{\mathrm{C}}$<smiles>Cc1ccc(Br)cc1</smiles>

$14^{\mathrm{d}}$<smiles>Ic1ccccc1I</smiles>

$15^{\mathrm{d}}$<smiles>Ic1cccc(I)c1</smiles>

16<smiles>COc1ccc(I)cc1</smiles>

$n-\mathrm{C}_{5} \mathrm{H}_{11}-\mathrm{SH}$

$n-\mathrm{C}_{7} \mathrm{H}_{15}-\mathrm{SH}$

17
10<smiles>COc1ccc(Sc2ccccc2)cc1C</smiles>

3 e

8<smiles>COc1ccc(Sc2ccc(C)cc2)cc1</smiles><smiles>Cc1ccc(Sc2ccccc2Sc2ccc(C)cc2)cc1</smiles>

8

10
$3 \mathrm{~m}$<smiles>Cc1ccc(Sc2cccc(Sc3ccc(C)cc3)c2)cc1</smiles>

84

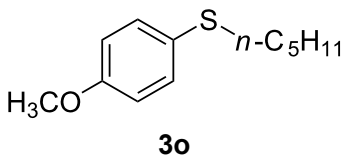

75

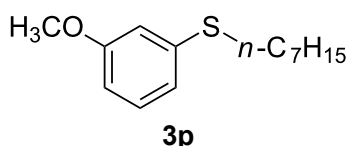<smiles>COc1cccc(I)c1</smiles>

aAryl halide (1 mmol), thiol (1.2 mmol), $\mathrm{K}_{2} \mathrm{CO}_{3}(1.2 \mathrm{mmol}), \mathrm{Ni} / \mathrm{RGO}-40(40 \mathrm{wt} \%, 22 \mathrm{mg})$ and DMF $(3 \mathrm{~mL})$ heated at $100{ }^{\circ} \mathrm{C}$ under nitrogen. ${ }^{\mathrm{b}} / \mathrm{solated}$ yield. ${ }^{C} Z n$ dust $(1 \mathrm{mmol})$ was added. ${ }^{\mathrm{d}}$ Aryl halide $(0.5 \mathrm{mmol}), 4$-methylphenylthiol $(1.2 \mathrm{mmol}), \mathrm{K}_{2} \mathrm{CO}_{3}(1.2 \mathrm{mmol}), \mathrm{Ni} / \mathrm{RGO}-40$ (40 wt $\left.\%, 22 \mathrm{mg}\right)$.

organonickel intermediate $\mathrm{Ar}-\mathrm{Ni}(\mathrm{II})-\mathrm{Br}$ (derived from the oxidative addition of $\mathrm{Ni}$ to the $\mathrm{Ar}-\mathrm{Br}$ bond) might not be sufficiently reactive to the thiolate anion $\left(\mathrm{Ar}-\mathrm{S}^{-} \mathrm{K}^{+}\right)$before being reduced to the organonickel species $[\mathrm{Ar}-\mathrm{Ni}(\mathrm{I})]$ in the presence of zinc. Diiodobenzenes, however, underwent smooth coupling affording the bis-coupled products $\mathbf{3 m}$ and $\mathbf{3 n}$ as the single products (Table 2, entries 14 and 15). Using aliphatic thiols has also resulted in the formation of unsymmetrical aryl alkyl thioether $\mathbf{3 o}$ and $\mathbf{3 p}$ in relatively lower yields (75-80\%; Table 2 , entries 16 and 17). Aliphatic thiols are, however, known to be less reactive as compared to aromatic thiols in coupling chemistry, which might be the reason to obtain lower yields [15].

\section{Reusability of the catalyst (Ni/RGO-40)}

After establishing the generality of RGO-supported Ni NPs size-specific catalytic efficiency in the $\mathrm{C}-\mathrm{S}$ coupling reaction, we recovered the catalyst from the reaction mixture (see Experimental section) and studied its reusability. Here, we used 4-iodoanisole and benzenethiol as the model coupling partners. It was found that the catalyst can be reused at least for six times for the same reaction examined consecutively without any sig- nificant drop in catalytic activity. Figure 1 shows the results of consecutive recycle runs.

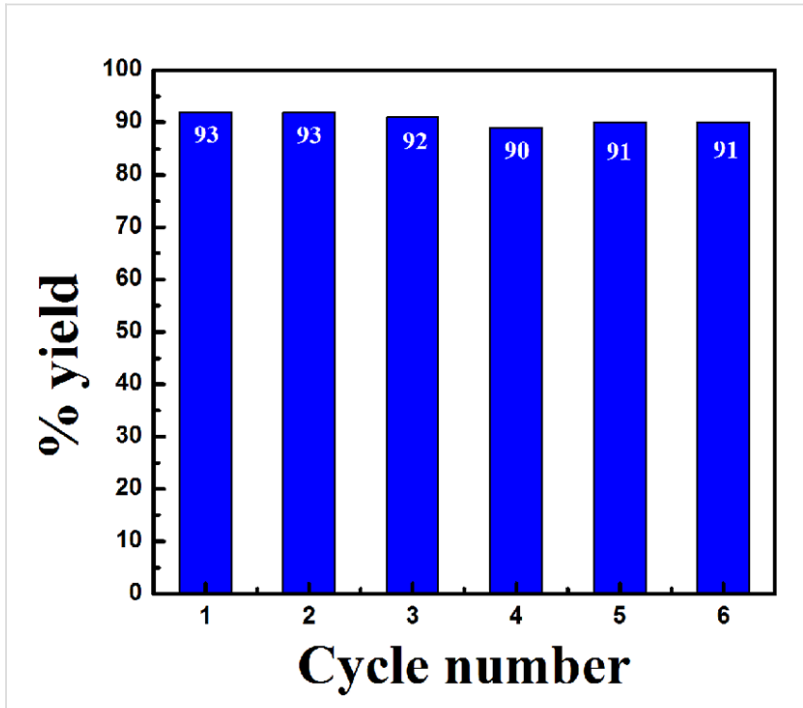

Figure 1: Recycling experiments of Ni/RGO-40 catalyst in C-S crosscoupling reaction between 4 -iodoanisole and benzenethiol. 


\section{Characterization of the recovered catalyst}

To establish the reaction mechanism, we characterized the recovered catalyst by Raman, XRD, XPS and TEM studies. The Raman and XRD results of fresh Ni/RGO-40 were reported in our previous publication [48]. However, for comparison, Raman and XRD of a fresh Ni/RGO-40 sample were again recorded and presented along with that of the recovered sample. The Raman spectrum of the Ni/RGO-40 composite (Figure 2a) exhibits a characteristic $\mathrm{D}$ band at $1344 \mathrm{~cm}^{-1}\left(\mathrm{~A}_{1 \mathrm{~g}}\right.$ vibrations of six-membered $\mathrm{sp}^{2}$ carbon rings) and the $\mathrm{G}$ band at $1580 \mathrm{~cm}^{-1}$ (first-order scattering of the $\mathrm{E}_{2 \mathrm{~g}}$ mode of $\mathrm{sp}^{2}$ domains). After the first run, the Raman spectrum of the recovered Ni/RGO-40 catalyst (Figure $2 b$ ), however, did not reveal any peak related to the nickel oxide $(\mathrm{NiO})$. The intensity ratio of the $\mathrm{D}$ over the $\mathrm{G}$ band was found to be 1.03 , which is similar to that of $\mathrm{Ni} / \mathrm{RGO}-40$ before used in the $\mathrm{C}-\mathrm{S}$ coupling reaction (Figure 2a). The powder XRD of Ni/RGO-40, recovered after the first cycle, was also recorded and is shown in Figure 3. The XRD pattern (Figure 3a) of the fresh sample shows peaks for $\mathrm{Ni}(111)$ and $\mathrm{Ni}(200)$ for $\mathrm{Ni}(0)$ being supported with RGO. The crystallite sizes of $\mathrm{Ni}(0)$ in the recovered catalyst were found to be $12 \mathrm{~nm}$, calculated by using the X-ray line broadening method based on (111), (200) peaks in Figure 3b. The particle size clearly indicates that the planar surface of RGO effectively prevents the agglomeration of Ni NP during the catalysis. Apart from the characteristic peaks of $\mathrm{Ni}(0)$, two additional peaks were observed in the XRD of the recovered catalyst (Figure $3 b$ ). These two peaks indicate the presence of $\mathrm{Ni}(\mathrm{OH})_{2}$. It was further confirmed by performing X-ray photoelectron spectroscopy (XPS) of the recovered catalyst (Figure 4). The XPS of fresh catalyst shows only $\mathrm{Ni}(0)$ related peaks [48]. The HRXPS of $\mathrm{Ni}$ in the recovered $\mathrm{Ni} / \mathrm{RGO}-40$ (Figure $4 \mathrm{a}$ ) clearly shows the

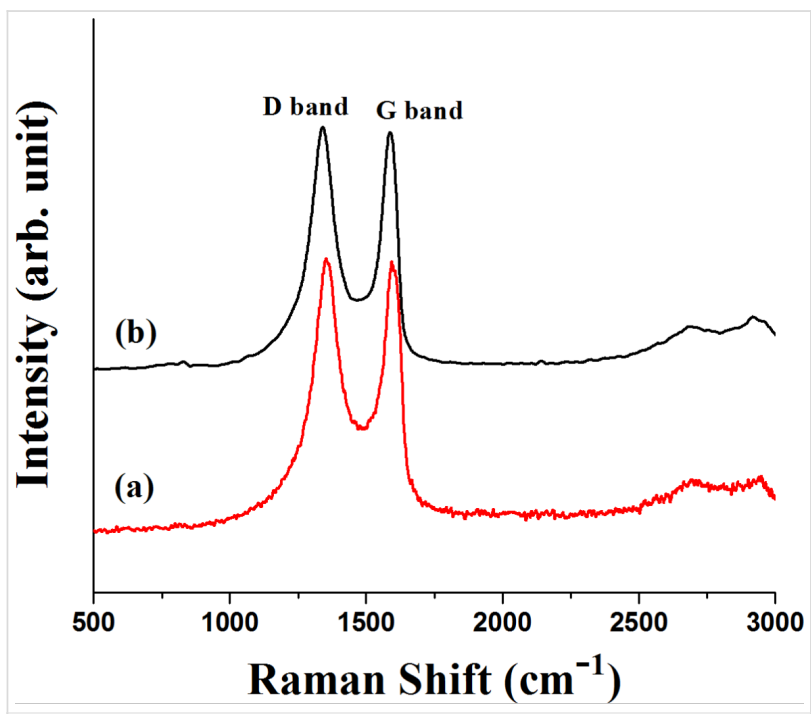

Figure 2: (a) Raman spectrum of fresh Ni/RGO-40 and (b) recovered catalyst after the first cycle of $\mathrm{C}-\mathrm{S}$ coupling.

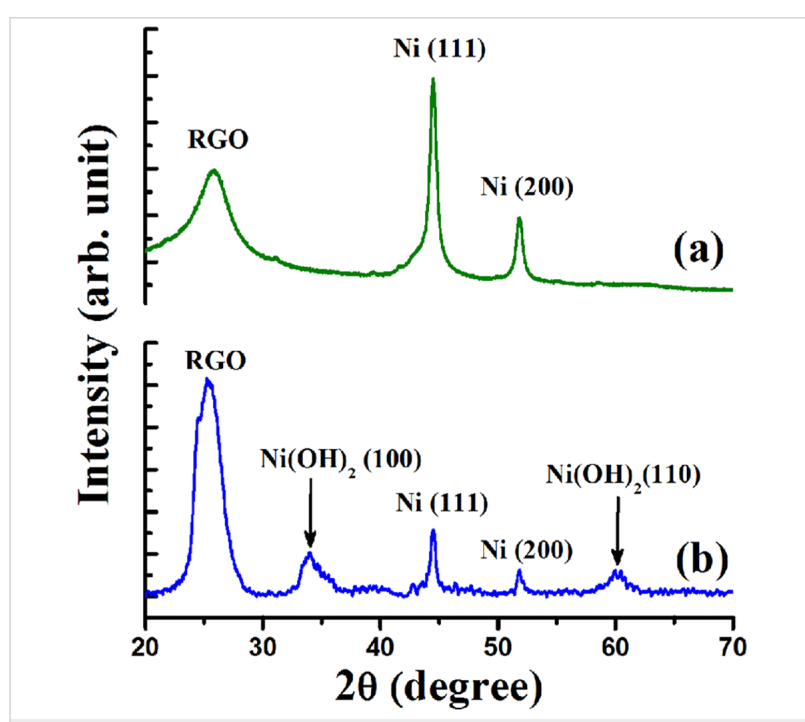

Figure 3: (a) XRD of fresh Ni/RGO-40 and (b) the recovered catalyst after the first cycle of $\mathrm{C}-\mathrm{S}$ coupling.
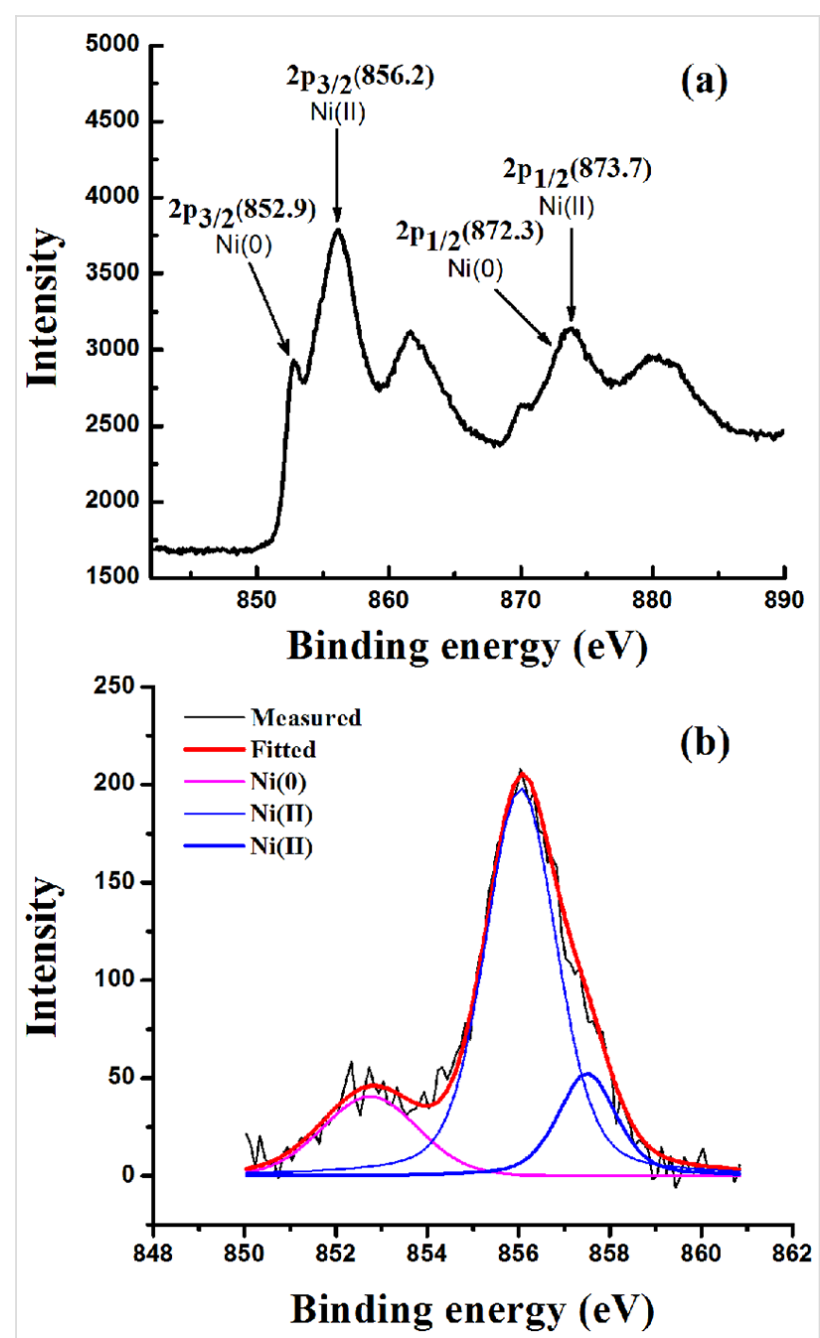

Figure 4: HRXPS of $\mathrm{Ni}$ in (a) Ni/RGO-40 catalyst recovered after the first cycle of the reaction. (b) Deconvoluted $2 p_{3 / 2}$ peak of Ni from (a). 
peak at $852.9 \mathrm{eV}$ corresponds to the $2 \mathrm{p}_{3 / 2}$ of the Ni(0) NPs [52]. Similarly the peak at $856.2 \mathrm{eV}$ represents the $2 \mathrm{p}_{3 / 2}$ of $\mathrm{Ni}(\mathrm{OH})_{2}$ [52]. The deconvoluted spectrum (Figure 4b) shows that the recovered catalyst contain $17 \% \mathrm{Ni}(0)$ and $83 \% \mathrm{Ni}(\mathrm{II})$ species. It was interesting to observe that in the recycle runs, which proceeded with excellent conversion to the thioether, the catalytic system contains a significant amount of Ni(II) species embedded with RGO in addition to Ni(0) NPs. Therefore, assuming that $\mathrm{Ni}$ (II) species having embedded with RGO can also be used as the catalytic system, we prepared a new nanocomposite $\left[\mathrm{Ni}(\mathrm{OH})_{2} / \mathrm{RGO}(30 \mathrm{wt} \%)\right]$ [48], with average particle size of $13 \mathrm{~nm}$ (calculated on the basis of Figure 5) and examined its catalytic efficiency in the $\mathrm{C}-\mathrm{S}$ cross-coupling reaction. We could achieve the $\mathrm{C}-\mathrm{S}$ coupled thioether product in $82 \%$ yield only, which is lower than Ni/RGO-40 (see Supporting Information File 1, Table S1, a Table showing comparative catalytic efficiency and NP sizes).

Mechanistically, the transition-metal-catalyzed C-S cross-coupling reaction, using mainly $\mathrm{Pd}, \mathrm{Cu}$ or Ni species, is believed to proceed through three major steps; viz. the initial oxidative addition, then substitution by thiolate anion and finally the reductive elimination. A more detailed study describing Pd- or $\mathrm{Cu}$-catalyzed $\mathrm{C}-\mathrm{S}$ coupling reactions as compared to $\mathrm{Ni}$-catalyzed reaction has been published $[7,53,54]$. However, as proposed in previous investigations on the Ni-catalyzed $\mathrm{C}-\mathrm{S}$ coupling reaction $[15,22,23]$, the catalytic cycle here is likely to occur in analogy. Examination of the recovered catalyst by HRXPS suggests that there is significant quantity of Ni(II)

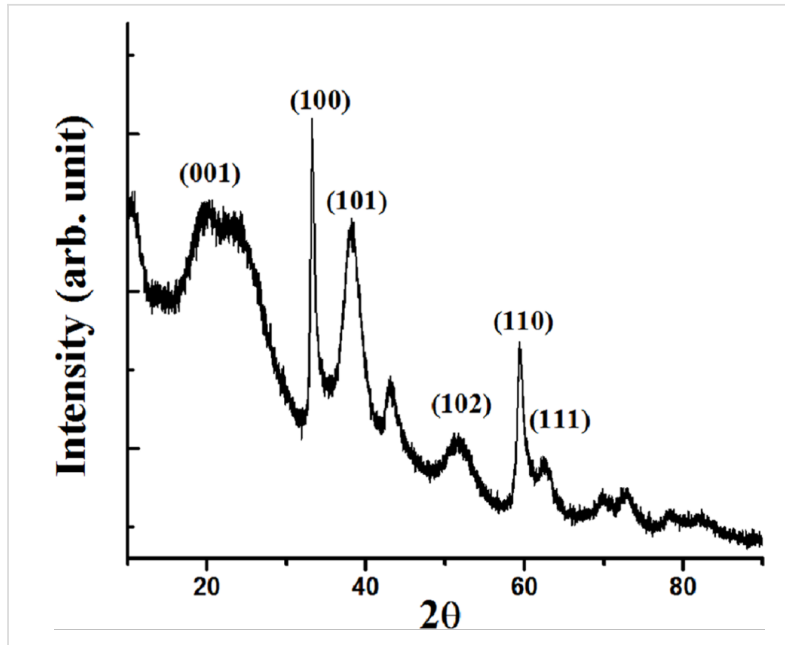

Figure 5: $\mathrm{XRD}$ of $\mathrm{Ni}(\mathrm{OH})_{2} / \mathrm{RGO}$, prepared separately.

hydroxide and interestingly that is also equally active in catalyzing the $\mathrm{C}-\mathrm{S}$ coupling reaction. Initial oxidative addition to an $\mathrm{Ar}-\mathrm{I}$ bond gives $\mathrm{Ar}-\mathrm{Ni}{ }^{\mathrm{II}}-\mathrm{I}$ followed by $\mathrm{Ar}-\mathrm{Ni}{ }^{\mathrm{II}}-\mathrm{SPh}$, and then the reductive elimination could result in the formation of $\mathrm{Ar}-\mathrm{SPh}$ (Figure 6). The resulting Ni(II) species could be converted mostly to $\mathrm{Ni}(\mathrm{OH})_{2} \mathrm{NPs}$ in the presence of water during washing and subsequent recovery, as examined from the powder XRD and HRXPS of the recovered catalyst after the first run (Figure $3 \mathrm{~b}$ and Figure $4 \mathrm{~b}$ ). In support of our proposed reaction mechanism, we analyzed the TEM images of the fresh $\mathrm{Ni} / \mathrm{RGO}-40$ catalyst and the recovered one after the first cycle of catalysis. In Figure 7a, we show the TEM image of fresh

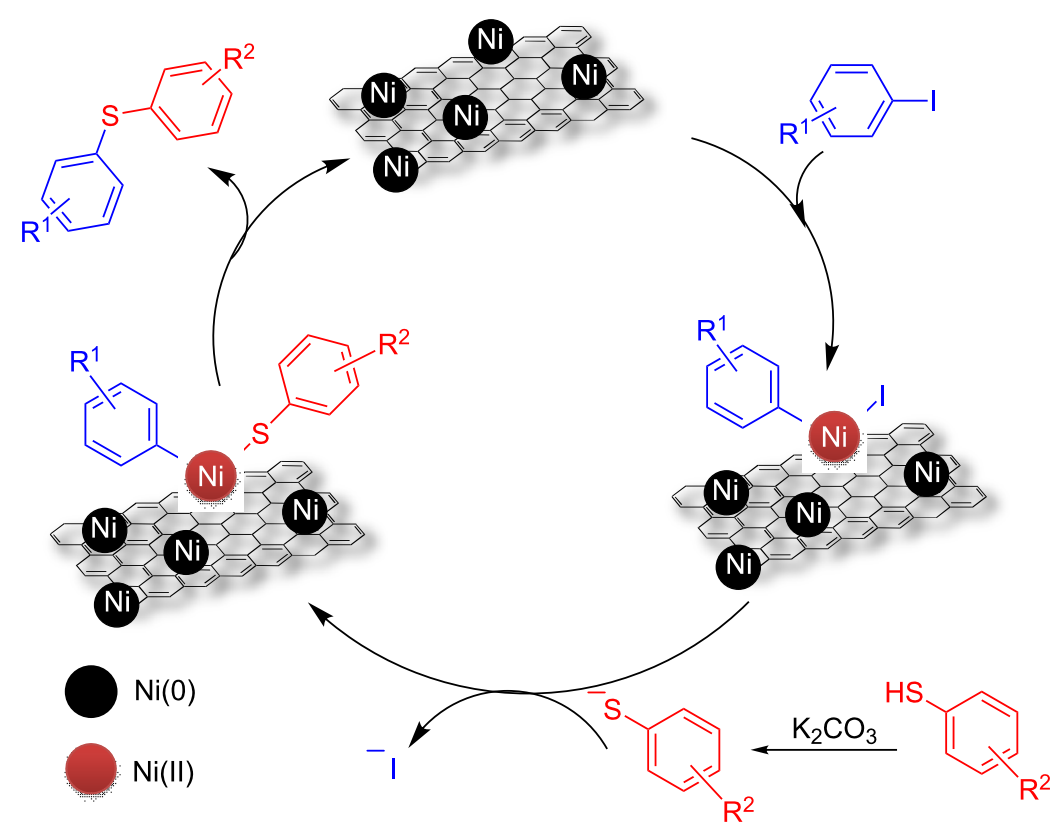

Figure 6: Proposed mechanism for the RGO-supported Ni-catalyzed C-S cross-coupling reaction. 

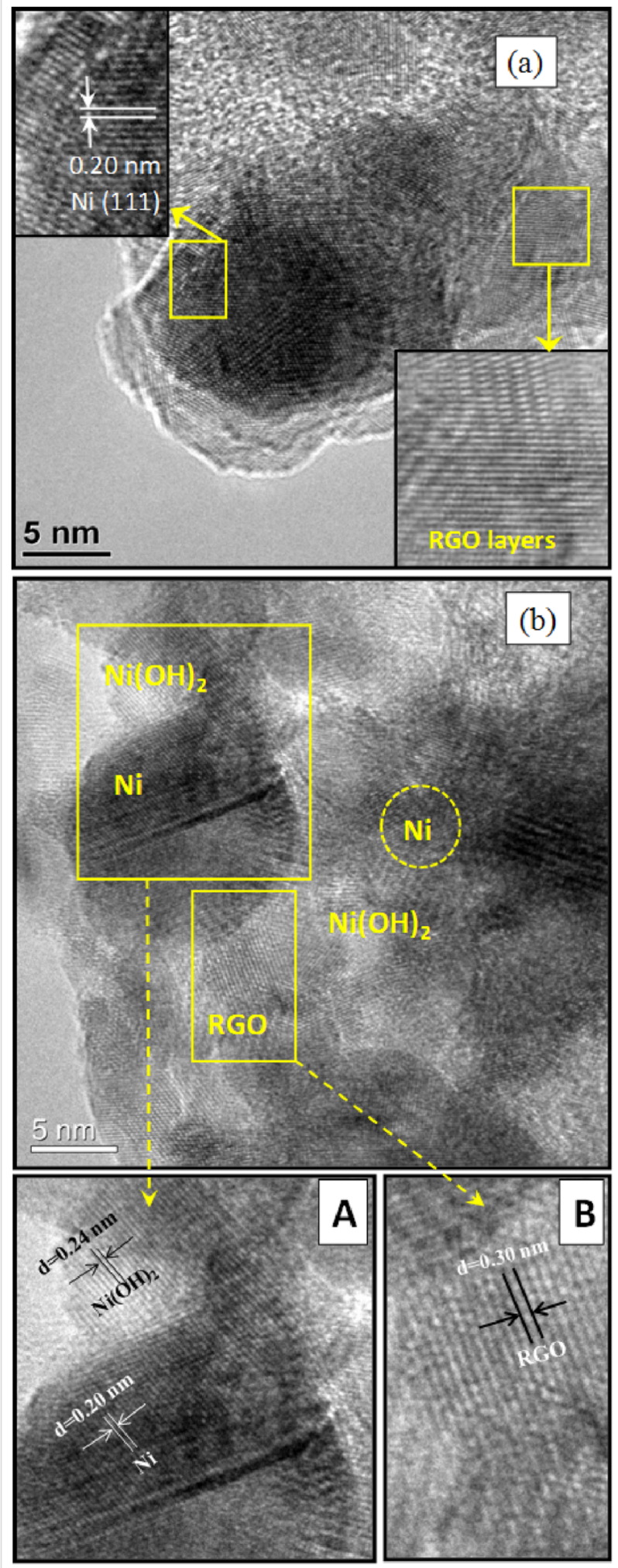

Figure 7: TEM image of (a) Ni/RGO-40 before usage as a catalyst (for comparison, reprinted with permission from [48], copyright 2014 American Chemical Society) and (b) recovered catalyst after the first cycle of reaction showing the different domains (marked by yellow enclosures). The enlarged views of the marked rectangular areas in (b) are shown in A (Ni species) and B (RGO).
$\mathrm{Ni} / \mathrm{RGO}-40$ (figure reproduced from our earlier publication, ref [48]) for comparison and that of the recovered $\mathrm{Ni} / \mathrm{RGO}-40$ is shown in Figure $7 \mathrm{~b}$. Figure $7 \mathrm{~b}$ clearly shows the presence of metallic Ni NPs and $\mathrm{Ni}(\mathrm{OH})_{2}$ on the RGO surface. One can observe the co-existence of crystalline fringes of $\mathrm{Ni}<111>$ and $\mathrm{Ni}(\mathrm{OH})_{2}<100>$ (inset A; Figure 7b) along with the interlayer spacing of RGO (inset B; Figure 7b). The particle size of Ni NPs observed from TEM image was almost similar in the before and after catalysis sample, i.e., around $11 \mathrm{~nm}$, indicating the particle agglomeration did not occur during the catalysis. Again, the crystallite size of the $\mathrm{Ni}(\mathrm{OH})_{2}$ was found to be around $4 \mathrm{~nm}$, which is corroborated from the X-ray line broadening method on the $<100>$ peak of $\mathrm{Ni}(\mathrm{OH})_{2}$ in Figure $3 \mathrm{~b}$. It is likely that $\mathrm{Ni}(\mathrm{OH})_{2}$ could form during the recovery of the catalyst. In the recycle run, the major catalytic constituent $\mathrm{Ni}(\mathrm{OH})_{2}$ is presumably reduced by thiolate anions to $\mathrm{Ni}(\mathrm{I})$ species, which then undergoes oxidative addition to the aryl halide forming a $\mathrm{Ni}(\mathrm{III})$ species, as proposed previously [19].

\section{Conclusion}

In conclusion, we have shown that a RGO-supported $\mathrm{Ni}(0)$ nanocomposite $(\mathrm{Ni} / \mathrm{RGO}-40)$ with average size $(\approx 11-12 \mathrm{~nm}) \mathrm{Ni}$ NPs display high catalytic efficiency for $\mathrm{C}-\mathrm{S}$ cross-coupling reactions and are applicable to a diverse range of coupling partners. The catalytic performance is primarily dependent on the NP sizes of the Ni species. The electron-rich planar surface of RGO helps in stabilizing the NPs and prevents agglomeration making them recyclable with almost equal efficiency. However, post-catalytic investigations of the heterogeneous catalyst reveal that the Ni NPs are considerably converted to $\mathrm{Ni}(\mathrm{OH})_{2}$, (average particle size $4 \mathrm{~nm}$ ) and remain closely associated with the Ni NPs on the electron-rich RGO surface and exhibit similar catalytic efficiency.

\section{Experimental}

Chemicals were used as received. For column chromatography, silica (60-120 mm, SRL, India) was used. For thin-layer chromatography (TLC), plates (Merck) coated with silica gel 60, $\mathrm{F}_{254}$ were used.

The progress of the reaction was monitored by HPLC (Agilent Technologies, 1260 Infinity), Column: ZORBAX Rx-SIL $(4.6 \times 150 \mathrm{~mm}, 5 \mathrm{~mm})$, eluent: $n$-hexane (flow rate $\left.2 \mathrm{~mL} \mathrm{~min}{ }^{-1}\right) .{ }^{1} \mathrm{H}$ and ${ }^{13} \mathrm{C}$ NMR spectra were taken in $\mathrm{CDCl}_{3}$ using a Bruker Avance AV-300 spectrometer operating at $300 \mathrm{MHz}$ and $75 \mathrm{MHz}$, respectively. Chemical shifts are reported relative to tetramethylsilane (TMS) served as the internal standard $(\delta=0 \mathrm{ppm}) .{ }^{13} \mathrm{C}$ NMR spectra were recorded with complete proton decoupling and chemical shifts are reported in ppm with the solvent resonance as the internal standard $\left(\mathrm{CDCl}_{3}\right.$ : $\delta=77.00 \mathrm{ppm}$ ). Raman spectra were obtained using Renishaw 
InVia Reflex micro Raman spectrometer with excitation of argon ion (514 nm) lasers. The laser power was kept sufficiently low to avoid heating of the samples and spectra were collected with a resolution of $1 \mathrm{~cm}^{-1}$. X-ray diffraction (XRD) studies of the powder samples were performed with Rigaku Smartlab X-ray diffractometer operating at $9 \mathrm{~kW}(200 \mathrm{~mA}$; $45 \mathrm{kV}$ ) using $\mathrm{Cu} \mathrm{K} \alpha$ radiation. X-ray photoelectron spectroscopic (XPS) measurements were done on a PHI 5000 Versaprobe II XPS system with Al K $\alpha$ source and a charge neutralizer at room temperature, maintaining a base pressure about $6 \times 10^{-10}$ mbar and energy resolution of $0.6 \mathrm{eV}$.

\section{General procedure for C-S cross-coupling using Ni/RGO-40}

A mixture of aryl halide $(1 \mathrm{mmol})$, thiol $(1.2 \mathrm{mmol})$, potassium carbonate (1.2 mmol), Ni/RGO-40 catalyst (22 mg; Ni content is $8.8 \mathrm{mg}, 0.15 \mathrm{mmol}, 15 \mathrm{~mol} \%)$ in DMF ( $3 \mathrm{~mL}$ ) were taken in a $15 \mathrm{~mL}$ sealed tube, flashed and filled with $\mathrm{N}_{2}$ gas and quickly screw-capped. The reaction mixture was then heated to $100{ }^{\circ} \mathrm{C}$ with a gentle magnetic stirring for hours. After completion of the reaction, the mixture was allowed to cool, diluted with ethyl acetate $(3 \mathrm{~mL})$, stirred gently and then allowed to stand for $15 \mathrm{~min}$. The supernatant liquid was carefully pipetted out into another flask and this process was repeated three more times. The organic part was washed with water, dried over anhydrous $\mathrm{Na}_{2} \mathrm{SO}_{4}$, concentrated to afford a residue, which was purified by column chromatography over a short column of silica gel and eluting with light petroleum to obtain pure sulfanes. All unsymmetrical sulfanes were characterized by ${ }^{1} \mathrm{H}$ and ${ }^{13} \mathrm{C}$ NMR and compared with the reported data (see Supporting Information File 1, pages S3-S6).

In order to recover the catalyst, the insoluble materials obtained after washing with ethyl acetate were thoroughly washed with water $(3 \times 3 \mathrm{~mL})$ followed by acetone $(3 \times 3 \mathrm{~mL})$ and then dried under vacuum to obtain a free-flowing black powder. This material was used for the next catalytic cycle.

\section{Gram-scale procedure for C-S cross- coupling using Ni/RGO-40}

A mixture of 4-iodoanisole (1 g, $4.27 \mathrm{mmol})$, thiophenol (0.563 g, $5.12 \mathrm{mmol})$, potassium carbonate $(0.706 \mathrm{~g}$, $5.12 \mathrm{mmol}), \mathrm{Ni} / \mathrm{RGO}-40$ catalyst $(94.0 \mathrm{mg}$; Ni content is $37.60 \mathrm{mg}, 0.64 \mathrm{mmol})$ in DMF (4 mL) were taken in a $15 \mathrm{~mL}$ sealed tube, flashed and filled with $\mathrm{N}_{2}$ gas and quickly screwcapped. The reaction mixture was then heated to $100{ }^{\circ} \mathrm{C}$ with a gentle magnetic stirring for 3 hours. After cooling the reaction mixture was diluted with ethyl acetate $(4 \mathrm{~mL})$, stirred gently and then allowed to stand for $15 \mathrm{~min}$. The supernatant liquid was carefully pipetted out into another flask and this process was repeated three more times. The organic part was washed with water, dried over anhydrous $\mathrm{Na}_{2} \mathrm{SO}_{4}$, and concentrated to afford a residue, which was purified by column chromatography over a short column of silica gel and eluting with light petroleum to obtain $0.85 \mathrm{~g}(92 \%)$ of pure (4-methoxyphenyl)(phenyl)sulfane as a colourless liquid.

\section{Supporting Information}

\section{Supporting Information File 1}

Powder XRD patterns of Ni/RGO-20 and Ni/RGO-40;

Table showing comparative catalytic performance and effect of NP sizes; ${ }^{1} \mathrm{H}$ and ${ }^{13} \mathrm{C}$ NMR spectral data for compounds $\mathbf{3 a}-\mathbf{p}$.

[http://www.beilstein-journals.org/bjoc/content/ supplementary/1860-5397-13-174-S1.pdf]

\section{Supporting Information File 2}

${ }^{1} \mathrm{H}$ and ${ }^{13} \mathrm{C}$ NMR spectra (scanned) for compounds $\mathbf{3 a}-\mathbf{p}$. [http://www.beilstein-journals.org/bjoc/content/ supplementary/1860-5397-13-174-S2.pdf]

\section{Acknowledgements}

Financial support from the Science and Engineering Research Board, New Delhi (No EMR/2015/000549) is gratefully acknowledged. DS and KB thank CSIR, India for providing fellowships.

\section{References}

1. Kaldor, S. W.; Kalish, V. J.; Davies, J. F.; Shetty, B. V.; Fritz, J. E.; Appelt, K.; Burgess, J. A.; Campanale, K. M.; Chirgadze, N. Y.; Clawson, D. K.; Dressman, B. A.; Hatch, S. D.; Khalil, D. A.; Kosa, M. B.; Lubbehusen, P. P.; Muesing, M. A.; Patick, A. K.; Reich, S. H.; Su, K. S.; Tatlock, J. H. J. Med. Chem. 1997, 40, 3979-3985. doi:10.1021/jm9704098

2. De Martino, G.; Edler, M. C.; Regina, G. L.; Cosuccia, A.; Barbera, M. C.; Barrow, D.; Nicholson, R. I.; Chiosis, G.; Brancale, A.; Hamel, E.; Artico, M.; Silvestri, R. J. Med. Chem. 2006, 49, 947-954. doi:10.1021/jm050809s

3. Liu, G.; Huth, J. R.; Olejniczak, E. T.; Mendoza, R.; DeVries, P.; Leitza, S.; Reilly, E. B.; Okasinski, G. F.; Fesik, S. W.; von Geldern, T. W. J. Med. Chem. 2001, 44, 1202-1210. doi:10.1021/jm000503f

4. Nielsen, S. F.; Nielsen, E. Ø.; Olsen, G. M.; Liljefors, T.; Peters, D. J. Med. Chem. 2000, 43, 2217-2226. doi:10.1021/jm990973d

5. Toshihiko, M.; Tomiya, S.; Yoriyoshi, A.; Jun-ichi, S.; Yasuki, K.; Masanori, K. Bull. Chem. Soc. Jpn. 1980, 53, 1385-1389. doi:10.1246/bcsj.53.1385

6. Cristau, H. J.; Chabaud, B.; Chêne, A.; Christol, H. Synthesis 1981, 892-894. doi:10.1055/s-1981-29636

7. Eichman, C. C.; Stambuli, J. P. Molecules 2011, 16, 590-608. doi:10.3390/molecules16010590

8. Wong, Y.-C.; Jayanth, T. T.; Cheng, C.-H. Org. Lett. 2006, 8, 5613-5616. doi:10.1021/ol062344| 
9. Correa, A.; Carril, M.; Bolm, C. Angew. Chem., Int. Ed. 2008, 47, 2880-2883. doi:10.1002/anie.200705668

10. Lai, C.-S.; Kao, H.-L.; Wang, Y.-J.; Lee, C.-F. Tetrahedron Lett. 2012 , 53, 4365-4367. doi:10.1016/j.tetlet.2012.06.054

11. Liu, T.-J.; Yi, C.-L.; Chan, C.-C.; Lee, C.-F. Chem. - Asian J. 2013, 8, 1029-1034. doi:10.1002/asia.201300045

12. Reddy, V. P.; Kumar, A. V.; Swapna, K.; Rao, K. R. Org. Lett. 2009, 11, 1697-1700. doi:10.1021/ol900009a

13. Malik, P.; Chakraborty, D. Appl. Organomet. Chem. 2012, 26 , 557-561. doi:10.1002/aoc.2871

14. Hegedus, L. L.; McCabe, R. W. Catalyst poisoning; Marcel Dekker: New York, 1984.

15. Jammi, S.; Barua, P.; Rout, L.; Saha, P.; Punniyamurthy, T. Tetrahedron Lett. 2008, 49, 1484-1487. doi:10.1016/j.tetlet.2007.12.118

16. Cao, Y.-Q.; Zhang, Z.; Guo, Y.-X.; Wu, G.-Q. Synth. Commun. 2008, 38, 1325-1332. doi:10.1080/00397910801914111

17. Percec, V.; Bae, J.-Y.; Hill, D. H. J. Org. Chem. 1995, 60, 6895-6903. doi:10.1021/jo00126a047

18. Xu, X.-B.; Liu, J.; Zhang, J.-J.; Wang, Y.-W.; Peng, Y. Org. Lett. 2013, 15, 550-553. doi:10.1021/ol303366u

19. Venkanna, G. T.; Arman, H. D.; Tonzetich, Z. J. ACS Catal. 2014, 4, 2941-2950. doi:10.1021/cs500874z

20. Zhang, J.; Medley, C. M.; Krause, J. A.; Guan, H. Organometallics 2010, 29, 6393-6401. doi:10.1021/om100816d

21. Yatsumonji, Y.; Okada, O.; Tsubouchi, A.; Takeda, T. Tetrahedron 2006, 62, 9981-9987. doi:10.1016/j.tet.2006.08.001

22. Zhang, Y.; Ngeow, K. C.; Ying, J. Y. Org. Lett. 2007, 9, 3495-3498. doi:10.1021/ol071248x

23. Guan, P.; Cao, C.; Liu, Y.; Li, Y.; He, P.; Chen, Q.; Liu, G.; Shi, Y. Tetrahedron Lett. 2012, 53, 5987-5992. doi:10.1016/j.tetlet.2012.08.055

24. Pal, N.; Bhaumik, A. Dalton Trans. 2012, 41, 9161-9169. doi:10.1039/C2DT30343D

25. Stankovich, S.; Dikin, D. A.; Dommett, G. H. B.; Kohlhaas, K. M.; Zimney, E. J.; Stach, E. A.; Piner, R. D.; Nguyen, S. T.; Ruoff, R. S. Nature 2006, 442, 282-286. doi:10.1038/nature04969

26. Balandin, A. A.; Ghosh, S.; Bao, W.; Calizo, I.; Teweldebrhan, D.; Miao, F.; Lau, C. N. Nano Lett. 2008, 8, 902-907. doi:10.1021/nl0731872

27. Loh, K. P.; Bao, Q.; Eda, G.; Chhowalla, M. Nat. Chem. 2010, 2, 1015-1024. doi:10.1038/nchem.907

28. Li, B.; Cao, H.; Yin, J.; Wu, Y. A.; Warner, J. H. J. Mater. Chem. 2012, 22, 1876-1883. doi:10.1039/C1JM13032C

29. Li, W.; Wang, F.; Liu, Y.; Wang, J.; Yang, J.; Zhang, L.; Elzatahry, A. A.; Al-Dahyan, D.; Xia, Y.; Zhao, D. Nano Lett. 2015, 15, 2186-2193. doi:10.1021/acs.nanolett.5b00291

30. Bai, H.; Li, C.; Shi, G. Adv. Mater. 2011, 23, 1089-1115. doi:10.1002/adma.201003753

31. Li, M.; Pan, Y.; Guo, X.; Liang, Y.; Wu, Y.; Wen, Y.; Yang, H. J. Mater. Chem. A 2015, 3, 10353-10359. doi:10.1039/C5TA00891C

32. Sabater, S.; Mata, J. A.; Peris, E. Organometallics 2015, 34, 1186-1190. doi:10.1021/om501040x

33. Zhang, P.; Zhang, X.; Zhang, S.; Lu, X.; Li, Q.; Su, Z.; Wei, G. J. Mater. Chem. B 2013, 1, 6525-6531. doi:10.1039/C3TB21270J

34. Balcioglu, M.; Rana, M.; Yigit, M. V. J. Mater. Chem. B 2013, 1, 6187-6193. doi:10.1039/C3TB20992J

35. Li, B.; Cao, H.; Shao, J.; Qu, M.; Warner, J. H. J. Mater. Chem. 2011, 21, 5069-5075. doi:10.1039/C0JM03717F
36. Zhang, X.-Y.; Li, H.-P.; Cui, X.-L.; Lin, Y. J. Mater. Chem. 2010, 20, 2801-2806. doi:10.1039/B917240H

37. Guo, S.; Wen, D.; Zhai, Y.; Dong, S.; Wang, E. ACS Nano 2010, 4, 3959-3968. doi:10.1021/nn100852h

38. Scheuermann, G. M.; Rumi, L.; Steurer, P.; Bannwarth, W.; Mülhaupt, R. J. Am. Chem. Soc. 2009, 131, 8262-8270. doi:10.1021/ja901105a

39. Kamal, A.; Srinivasulu, V.; Murty, J. N. S. R. C.; Shankaraiah, N.; Nagesh, N.; Srinivasa Reddy, T.; Subba Rao, A. V. Adv. Synth. Catal. 2013, 355, 2297-2307. doi:10.1002/adsc.201300416

40. Zhang, N.; Qiu, H.; Liu, Y.; Wang, W.; Li, Y.; Wang, X.; Gao, J. J. Mater. Chem. 2011, 21, 11080-11083. doi:10.1039/C1JM12539G

41. Feng, Y.-S.; Lin, X.-Y.; Hao, J.; Xu, H.-J. Tetrahedron 2014, 70, 5249-5253. doi:10.1016/j.tet.2014.05.083

42. Zhai, Z.; Guo, X.; Jiao, Z.; Jin, G.; Guo, X.-Y. Catal. Sci. Technol. 2014, 4, 4196-4199. doi:10.1039/C4CY01048E

43. Yan, J.-M.; Zhang, X.-B.; Han, S.; Shioyama, H.; Xu, Q. Inorg. Chem. 2009, 48, 7389-7393. doi:10.1021/ic900921m

44. Lipshutz, B. H.; Tasler, S. Adv. Synth. Catal. 2001, 343, 327-329. doi:10.1002/1615-4169(20010430)343:4<327::AID-ADSC327>3.0.CO; 2-R

45. Lipshutz, B. H.; Frieman, B. A.; Lee, C.-T.; Lower, A.; Nihan, D. M.; Taft, B. R. Chem. - Asian J. 2006, 1, 417-429. doi:10.1002/asia.200600031

46. Soulé, J.-F.; Miyamura, H.; Kobayashi, S. J. Am. Chem. Soc. 2013, 135, 10602-10605. doi:10.1021/ja404006w

47. Hussain, N.; Gogoi, P.; Khare, P.; Das, M. R. RSC Adv. 2015, 5, 103105-103115. doi:10.1039/C5RA22601E

48. Bhowmik, K.; Mukherjee, A.; Mishra, M. K.; De, G. Langmuir 2014, 30, 3209-3216. doi:10.1021/la500156e

49. Bhowmik, K.; Sengupta, D.; Basu, B.; De, G. RSC Adv. 2014, 4, 35442-35448. doi:10.1039/C4RA04834B

50. Mandal, B.; Basu, B. RSC Adv. 2014, 4, 13854-13881. doi:10.1039/C3RA45997G

51. Wu, S.-H.; Chen, D.-H. J. Colloid Interface Sci. 2003, 259, 282-286. doi:10.1016/S0021-9797(02)00135-2

52. Husin, H.; Su, W.-N.; Chen, H.-M.; Pan, C.-J.; Chang, S.-H.; Rick, J.; Chuang, W.-T.; Sheu, H.-S.; Hwang, B.-J. Green Chem. 2011, 13, 1745-1754. doi:10.1039/C1GC15070G

53. Rout, L.; Saha, P.; Jammi, S.; Punniyamurthy, T. Eur. J. Org. Chem. 2008, 640-643. doi:10.1002/ejoc.200700978

54. Schwab, R. S.; Singh, D.; Alberto, E. E.; Piquini, P.; Rodrigues, O. E. D.; Braga, A. L. Catal. Sci. Technol. 2011, 1, 569-573. doi:10.1039/C1CY00091H 


\section{License and Terms}

This is an Open Access article under the terms of the Creative Commons Attribution License

(http://creativecommons.org/licenses/by/4.0), which permits unrestricted use, distribution, and reproduction in any medium, provided the original work is properly cited.

The license is subject to the Beilstein Journal of Organic Chemistry terms and conditions:

(http://www.beilstein-journals.org/bjoc)

The definitive version of this article is the electronic one which can be found at:

doi:10.3762/bjoc.13.174 